\title{
Scientific and practical substantiation of geodetic and topographic works using GIS software in the design of hydraulic structures
}

\author{
Kholmurod Khayitov ${ }^{1}$ and Nilufar Avilova ${ }^{1 *}$ \\ ${ }^{1}$ Tashkent Institute of Irrigation and Agricultural Mechanization Engineers, Kari-Niyazi 39, 100000, \\ Tashkent, Uzbekistan
}

\begin{abstract}
In this article, the scientific and practical basis of geodetic and topographic work in the design of hydraulic structures and solutions intended to improve them using GIS (Geoinformation Systems) were analysed. Geodetic and topographic works are the basis for the design, construction and reconstruction of hydraulic structures in Uzbekistan. A systematic approach to the analysis of geodetic and topographic works in the design of hydraulic structures was chosen, which was used to determine the essence of the processes and laws of scientific substantiation of projects of various hydraulic structures. The geological and topographic works were carried out to monitor the condition of the Karshi main canal, and besides, several other irrigation canals in the Kashkadarya region of the Republic of Uzbekistan were studied. The main task of the Karshi main canal is to supply water to various industries, offices, institutions and irrigation canals. After taking the horizontal and vertical topographic data of the Hisorak Reservoir and processing it using the Global Mapper software, a 3D dimensional model of the Hisorak Reservoir was created.
\end{abstract}

\section{Introduction}

A number of modern geodetic instruments in the design of hydraulic structures and GIS technologies are currently used for geodetic-topographic field surveys, the organization of the process of achieving effective results, the rapid and efficient mapping of geodetic works [1-4]. Many works are underway to ensure the safety of hydraulic structures and their regular monitoring around the world. On May 1, 2020, 6 picket walls of the Syrdarya Reservoir of the Republic of Uzbekistan were flooded. Therefore, it is vitally important to regularly monitor, control and ensure the deformation of dams in reservoirs. Obviously, damage to dams poses a serious threat to the environment and human life and economic problems. The implementation of new measures and solutions for regular monitoring of the deformation of large dams can prevent and control major hazards [1, 5].

In the design of hydraulic structures, initially geodetic work was carried out with the help of levels. The longitudinal profile of the river is the main document in the design of various hydraulic structures. The water levels of the characteristic points in a large part of

* Corresponding author: nilufaravilova@mail.ru 
the river are determined towards creating a longitudinal profile. The main reason are that this level is constantly changing and leveling cannot be done in all parts of the river at the same time. Therefore, it is necessary to simultaneously measure the height measurements made at different times in different parts. A high-precision leveling path is laid along one bank of the river to create a longitudinal profile. From these points, altitude marks are given to working rappers near the riverbed [7-9, 11]. Working rappers are used to level the water surface of the river, and it requires a lot of manpower as well as time. However, there is possibilities of getting better results in the design of hydraulic structures through enhancing geodetic works using GIS software [2].

A number of GIS software have been used in the design of hydraulic structures to analyse and apply to production processes carried out mainly on the basis of geodetic and topographic surveys. GIS software can be used in geodetic and topographical research through considering type and scope of research [5]. Mainly mainly geodetic and topographic field surveys are carried out to design hydraulic structures in reservoir, canals and rivers. Considering the function of hydraulic structures, primary and secondary types are identified, and major observed hydraulic structures are dams, water intakes and drainage structures. In turn, drainage facilities are subdivided into canals, reservoirs, and reservoirs that serve to remove excess water.

The squence of geodetic and topographic works is carried out as following [6]: 1) to determine boundaries of reservoir, 2) to research volume of water in reservoir and area of burial, 3) to identify flood-prone settlements, roads, power lines, calculation of damage costs, design of new settlements, and 4) to enhance the project of engineering constructions of protection of the city and various settlements from flooding. A reservoir is defined as an artificial reservoir built to collect and store water using dams, whereas a canal is a specially dug waterway that is a key part of an irrigation system. Depending on the function of the canals, they are divided into trunk, distribution, and economic types [4, 9]. Clearly, trunk canals deliver water from the reservoir to the distribution canal; direct distribution canals supply water to farm canals. Through farm canals, water is taken to canals and delivered to agriculture and other areas. Noteworthy, the main task of designing, constructing and renovating hydraulic structures is to some extent a solution to the global water shortage [9]. Before considering building large dams, it is important to ensure and think about safety, because damage to dams can be devastating. Therefore, it is advisable to thoroughly analyse and implement all topographic and geodetic works in the construction of dams [11]. Deformation of dams should be monitored regularly. In many countries, the status of reservoirs is now monitored by creating a 3D model of them in the Global Mapper software [10-11]. In Uzbekistan, it is necessary to develop and implement recommendations for the application of this research in reservoirs and other hydraulic structures. Prelimanary research showed that there was necessity for further research in designing, constructing and renovating hydraulic structures, therefore this research is intended to improve geodetic and topographic work using GIS software in the design of hydraulic structures.

\section{Materials and methods}

In this research, the Hisorak Reservoir in the Kashkadarya Region of the Republic of Uzbekistan was selected as study site. The reservoir was built on the Aksu River, a tributary of the Kashkadarya River in the Kashkadarya Region. The Hisorak Reservoir is equipped with dams, drainage, drainage facilities, water supply and drainage canals, and drainage networks. In the design (reconstruction, repair, monitoring and reconstruction) of each hydraulic structure, the topographic and geodetic details of the site were studied first [10]. Topographic and geodetic data of location, relief and elevation were collected. In the most 
of developing countries, the construction of small reservoirs is aimed at irrigating crops, supplying water and solving water-related problems [11].

Much attention was paid to the construction of dams in the reservoirs. Topographic and geodetic works for the construction of dams were carried out in the following order [10] Firstly, topographic and geodetic study of the dam under construction was done, in which data of the previous topographic and geodetic works was collected, coordinates as well as elevation details were studied, and scale data of the study site was gathered using hydrographic maps. Secondly, the planned heights in relation to geodetic points were researched towards ensuring the safety of the dam under construction [5-6,9]. Thirdly, the gathered data of topographic and geodetic works were analyzed and the most suitable geodetic as well as technical design for the construction of the dam was developed. It is necessary to process satellite images of the existing hydraulic structure under construction towards monitoring and repairing reservoir through employing GIS software and creating a 3D model of Global Mapper [10, 11]. In the study, a 3D model of the Hisorak Reservoir in Kashkadarya Province using the Global Mapper software was created to monitor the rise of dams and other hydraulic structures in the reservoir.

The geological and topographic works were carried out to monitor the condition of the Karshi main canal, and besides, several other irrigation canals in the Kashkadarya region of the Republic of Uzbekistan were studied. The main task of the Karshi main canal is to supply water to various industries, offices, institutions and irrigation canals. Topographic surveys was played an important role in the design, construction and monitoring of existing canals. Replacing the scale of topographic surveys with approximate, smaller ones saved time and manpower [4-6, 8].

\section{Results and discussion}

A removal of anything in the design of hydraulic structures should be the based on geodetic-topographic survey work as indicated as relief, elevation data. Important point is to open the file where the altitude database is stored, and the software describes the terrain based on elevation data, which makes the use of map a bit complicated. However, it can be solved using the software, and for this, thematic map has to be linked to the relief map. Accordingly, the the software first places a relief image of the place on it with a themed card. An altitude database and raster images are needed to create 3D geotags using GIS technology. Global Mapper can read altitude data in hgt format. There are several types and views of hgt altitude database downloads. Name of the selected area and corresponding coordinates appear on the left side of the map (Fig. 1) when the function in the working window is selected, especially in the software Global Mapper.

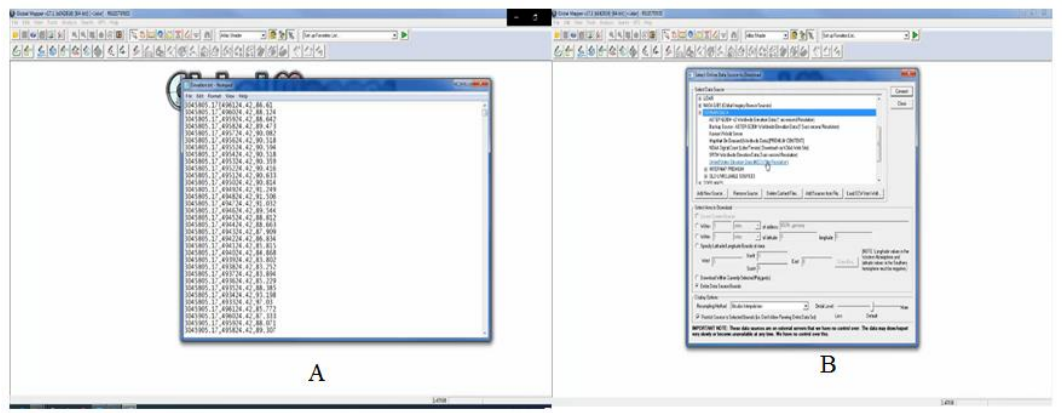

Fig. 1. Process of analysis of the coordinate system of the Hisorak reservoir in the Kashkadarya region of the Republic of Uzbekistan. 
The given coordinate system can be replaced with the desired coordinates at the desired distance and width. When the Raster Exporter button at the bottom of the window is selected, and the height database of the selected area will appear as a zip file. When this file is selected by users, the database is automatically uploaded to user computer, which shows where and how to copy the necessary files. In the download process, it is recommended to name the area in the file, which contains the altitude data. For example, it can be considered as an altitude map of Karshi city. The software describes the relief of the selected area in the nomenclature. The left and right sides of the image, along with the grids, show the cartographic distance and latitude. In addition, on the left side of the software window, the elevation data of the area are displayed in color in a hypsometric way. The reference points can be the intersection of topographic networks, land use turning points, and landmarks, and in the final stage, an image edit dialog box appears (Fig. 2).

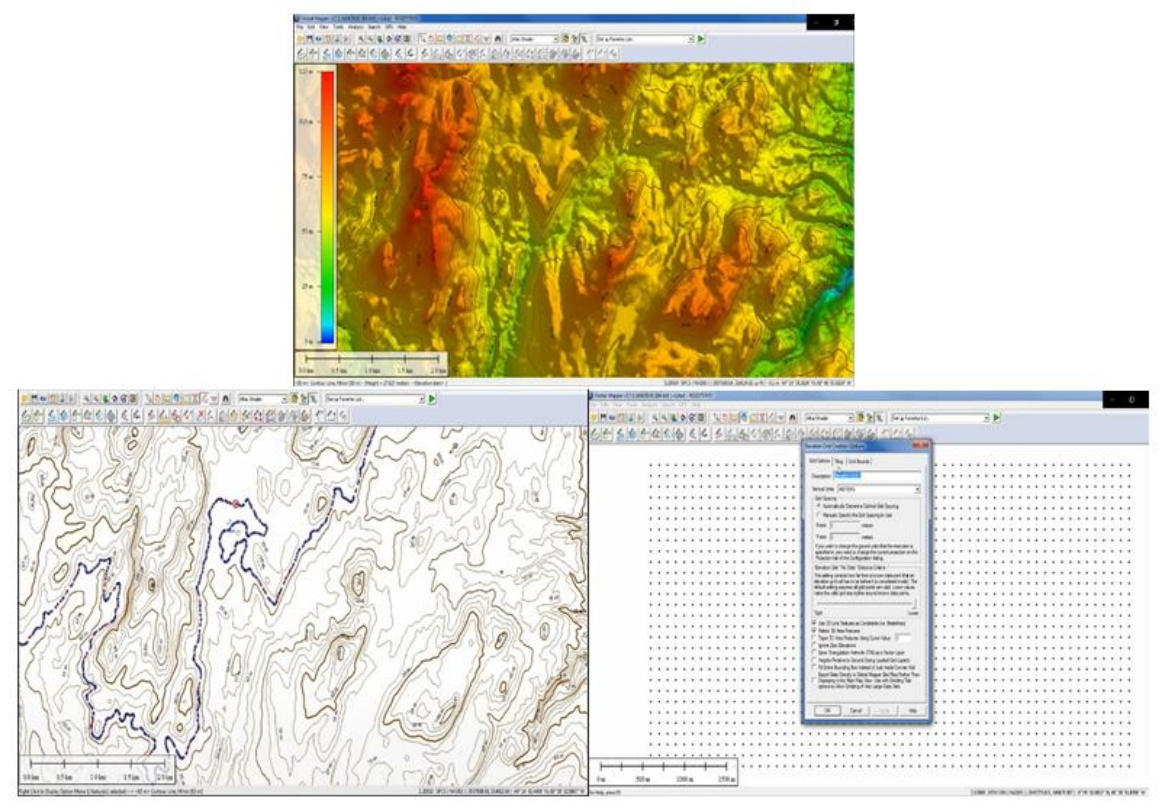

Fig. 2. Process of analysis of the coordinate system of the Hisorak reservoir in the Kashkadarya region of the Republic of Uzbekistan.

This dialog shows 3 different types of windows. Accordingly, window 1 shows our initial topographic raster map, window 2 shows a magnified map (to select coordinate values), and window 3 shows a relief map. Enlarge the map in window 2, select point 1, and in point 3 , select the location that corresponds to this coordinate, and place point 1 . Then click "Add Point", "Add Point" and save the checkpoint. In this way, at least 4 highresolution dots can be selected and stored in the database. Once, the points are saved, the "Accept" button needs to be clicked, which help to accept the entered coordinate points (Fig. 3). 


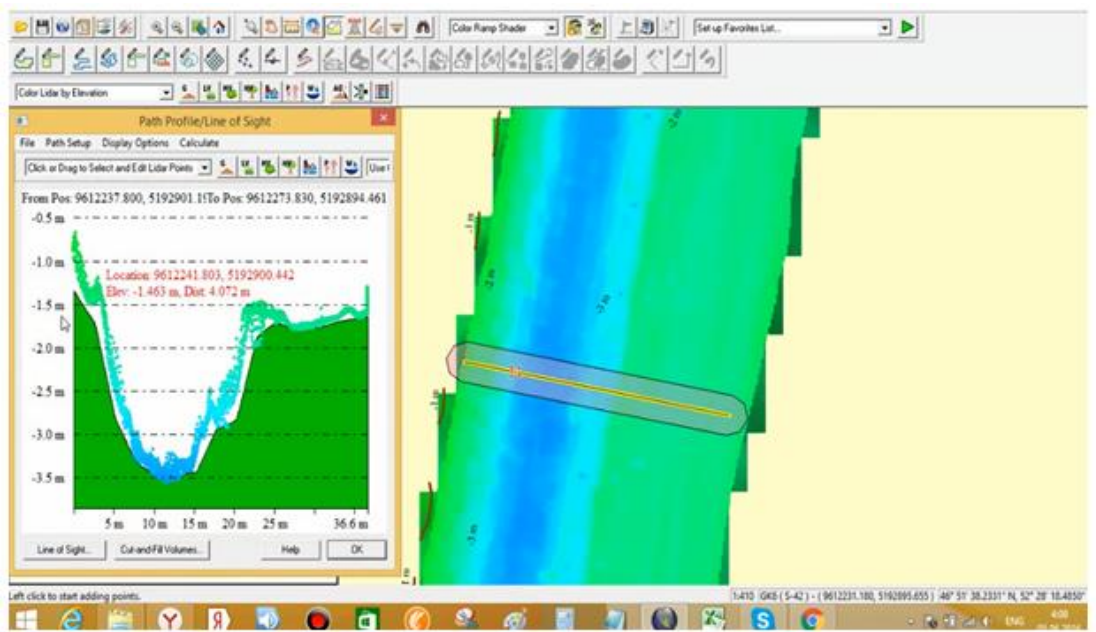

Fig. 3. Process of obtaining horizontal topographic data of the reservoir.

After taking the horizontal and vertical topographic data of the Hisorak Reservoir and processing it using the Global Mapper software, a 3D dimensional model of the Hisorak Reservoir was created (Fig. 4). The results of field research obtained during these hydraulic works and geodetic topographic surveys carried out at hydraulic structures were produced directly on the basis of the GIS program in the conditions of the chambers. The application of topographic prospecting in fast, convenient, error-free and efficient production was highlighted in the research results.

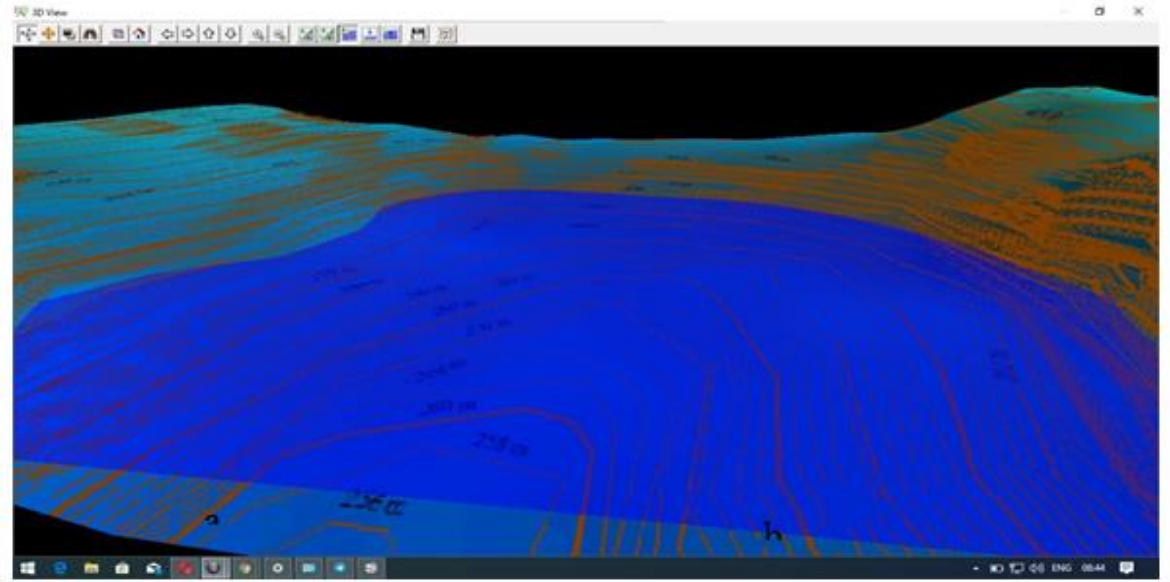

Fig. 4. 3D model of Hisorak reservoir, Kashkadarya region, Uzbekistan.

\section{Conclusions}

The analysis of the research experiment showed that data processing, analysis and design markings in the design and construction of reservoirs and canals were a very complex and laborious process. The use of the Global Mapper software, which belongs to the family of GIS technologies, can decrease the cost of obtaining geodetic and topographic data, and save time and money. The results of geodetic and topographic surveys can be used directly in the design of hydraulic structures, especially in the production of a number of markings, 
elevations and planned data in the process of topographic search of reservoirs and canals, as well as to update the workload.

A 3D dimensional model of the Hisorak reservoir in Kashkadarya region was created using the Global Mapper program, which help monitoring the condition of dams in the Hisorak reservoir and the rising state, in comparison with the previous condition. Consequently, it can allow prevent risk and ensure security in the design and construction of reservoirs and canals.

\section{References}

1. A. Chrzanowski, A. Szostak, R. Steeves, In Proceedings of the CDA 2011 Annual Conference, 45-49 (Fredericton, Canada, 2011)

2. R. Oymatov, S. Safayev, E3S Web of Conferences, 258, 03020 (2021)

3. N. Sabitova, O. Ruzikulova, I. Aslanov, E3S Web of Conferences, 227, 03003 (2021)

4. R. Kulmatov, S. Khasanov, S. Odilov, F. Li, Water, Air, and Soil Pollution, 232(5), $216(2021)$

5. SH. K. Avchiyev, Applied Geodesy, 350 (VORIS-NASHRIYOT, Tashkent, 2010)

6. F.A. Gapporov, D.N. Valijonov, S.R. Mansurov, Utilization of Water Reservoirs, 299 (TIIAME Publications, Tashkent, 2019)

7. M. Bakiyev, N. Rahmatov, A. Ibraymov, Utilization of hydro-technical constructions in irrigation canals, 279 (TIIAME Publications, Tashkent, 2018)

8. F.A. Fitzpatrick, In Developments in Earth Surface Processes, 18 (2014)

9. M. Scaioni, M. Marsella, M. Crosetto, V. Tornatore, J. Wang, Sensors, 18, 11 (2018)

10. J. Casaca, M. J. Henriques, International Federation of Surveyors International Congress, 22 (2002)

11. S. Islamov, N. Namozov, M. Saidova, D. Kodirova, E3S Web of Conferences, 244, 03028 (2021) 